Case Report

\title{
Diffuse B Cell Non-Hodgkin's Lymphoma Presenting Atypically as Periprosthetic Joint Infection in a Total Hip Replacement
}

\author{
Aysha Rajeev, ${ }^{1}$ Angela Ralte, ${ }^{2}$ Nameer Choudhry, ${ }^{1}$ Faizan Jabbar, ${ }^{1}$ and Paul Banaszkiewicz ${ }^{1}$ \\ ${ }^{1}$ Department of Trauma and Orthopaedics, Queen Elizabeth Hospital, Gateshead Health NHS Foundation Trust, \\ Sheriff Hill, Gateshead NE9 6SX, UK \\ ${ }^{2}$ Department of Pathology, Queen Elizabeth Hospital, Gateshead Health NHS Foundation Trust, Sheriff Hill, \\ Gateshead NE9 6SX, UK \\ Correspondence should be addressed to Aysha Rajeev; asrajeev18@gmail.com
}

Received 22 February 2017; Revised 20 April 2017; Accepted 30 April 2017; Published 24 May 2017

Academic Editor: Paul E. Di Cesare

Copyright (C) 2017 Aysha Rajeev et al. This is an open access article distributed under the Creative Commons Attribution License, which permits unrestricted use, distribution, and reproduction in any medium, provided the original work is properly cited.

The occurrence of extranodal primary B cell non-Hodgkin's lymphoma is rare. Total hip replacement is one of the most common orthopaedic procedures performed. There has been an increased incidence of primary lymphomas involving periprosthetic sites. Chronic inflammation due to metal debris arising from the prosthetic implants has been evidenced as one of the causes for the development of soft tissue lymphomas albeit rarely. We describe a case report of a 77-year-old patient who had underwent a cemented total hip replacement in the past who further developed large B cell primary non-Hodgkin's lymphoma. She presented initially with signs and symptoms highly suggestive of underlying periprosthetic infection. The radiological imaging was also indicative of periprosthetic infection. The diagnosis was eventually confirmed after an open biopsy. This case underlines the importance of considering and including soft tissue malignancy in the differential diagnosis of suspected chronic periprosthetic infection.

\section{Introduction}

Primary non-Hodgkin's lymphoma (NHL) is a rare malignancy of the musculoskeletal system and is known to affect up to $5-25 \%$ of patients $[1,2]$. Within the joint it can either affect the synovium [3] or directly involve the intra-articular tissue [1]. The patients often present with joint pain if the bone is affected primarily [4]. It is important to appreciate that lymphomas can involve extra-articular tissue and potentially mimic infection [5]. It has also been shown that patients with inflammatory arthritis have a higher incidence of hematopoietic cancers especially after joint replacement surgery $[6,7]$. Diffuse B cell NHL usually affects patients above 60 years of age and is known to be a very aggressive tumour [8].

We describe a unique and rare case report of a patient who presented with signs and symptoms suggestive of periprosthetic joint infection after total hip replacement, which finally concluded to have been diffuse B cell non-Hodgkin's lymphoma.

\section{Case Presentation}

A 77-year-old woman presented to our Accident and Emergency department with a one-year history of a painful right hip replacement. She complained of difficulty in weight bearing and a gradually diminishing walking distance such that in the four weeks prior to admission she was essentially housebound. Furthermore she reported her hip pain had progressed to an extent that it was present at rest and on occasion woke her up from sleep at night.

She had been reviewed six months previously by her local GP who had started her on high dose oral steroids for a provisional diagnosis of polymyalgia rheumatic under the guidance of the rheumatologist. There was no history of trauma.

Her past medical history included osteoarthritis, iron deficiency anemia, and a right cemented Exeter total hip replacement performed three years previously.

On examination she appeared generally unwell and frail. She was apyrexial with no evidence of any localized features 


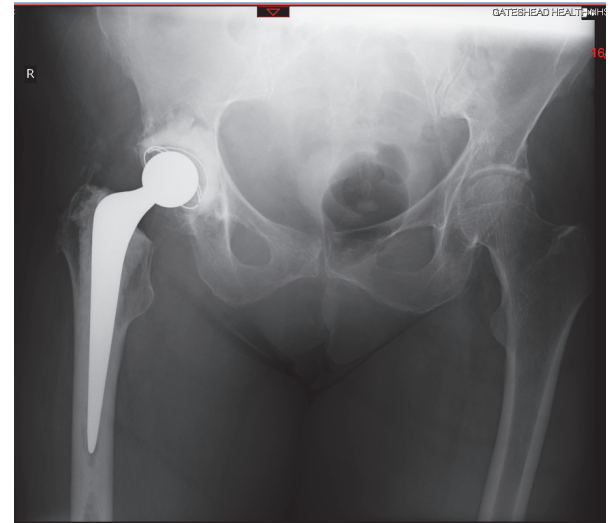

FIGURE 1: Plain X-ray of the right hip with normal soft tissues and satisfactory position of prosthesis.

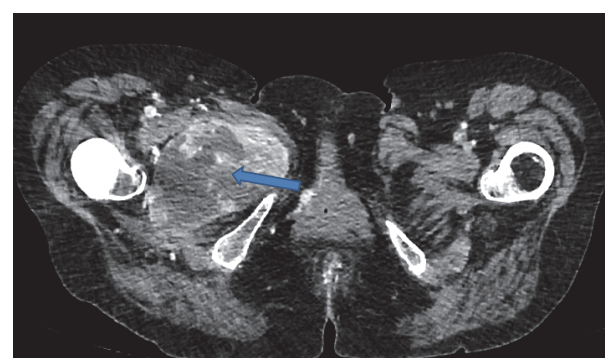

FIgURE 2: CT scan of the pelvis showing a cystic lesion in close proximity to the femoral stem suggesting an inflammatory pathology.

of erythema, swelling, redness, or skin changes around the affected hip. There was severe tenderness on palpation around the greater trochanter. Her active range of motion of the right hip was limited to $20^{\circ}$ flexion with all other movements being severely restricted. Passive range of motion was also limited.

The blood results showed a haemoglobin of 86 with an elevated WCC 32.5, CRP 246, and ESR 100. Plain X-rays of the hip were normal (Figure 1) and further cross-sectional CT imaging demonstrated a cystic mass closely related to the hip prosthesis suggesting an inflammatory pathology (Figure 2). The bone scan using Te $\mathrm{T}^{99}$ and SPECT (Single Photon Emission Computed Tomography) showed a large an area of intense hypervascularity at the medial aspect of the right proximal femur (Figures 3(a), 3(b), and 3(c)). The MRI scan revealed huge lesion with solid components and areas of liquefaction necrosis involving the periarticular hip region (Figures 4(a) and 4(b)). In view of the fact that the patient has got clinical signs and symptoms of sepsis and the imaging investigations pointing towards and infective pathology a provisional diagnosis of periprosthetic hip infection was made.

A hip aspiration was performed in theatre under image intensifier guidance with strict aseptic conditions. The aspirate revealed slightly turbid fluid. The following results including Gram stain, culture, and sensitivity were negative. Postaspiration intravenous antimicrobials were commenced. However the patient continued to remain unwell despite antimicrobial therapy with a progressively increasing WBC and CRP count. The decision was therefore taken to explore and perform open biopsy of the pelvic collection and soft tissue mass. At surgical exploration, a $4 \mathrm{~cm} \times 6 \mathrm{~cm}$ cavity was identified. Deep tissues were noted to be oedematous, necrotic, and inflamed, but macroscopically they were not typical findings in keeping with an abscess cavity. Specimens were sent for histology and microbiology. All direct culture and sensitivity specimens from the hip biopsy were negative. Histopathology of the specimen demonstrated sheets of atypical lymphoid cells with a hint of plasmacytoid differentiation (Figure 5). Immunostains showed the neoplastic cells to express CD138, MUM 1, PAX5, and EBV ISH (Figures 6(a), 6(b), 6(c), and 6(d)). They demonstrated patchy weak expression of CD56 and CD30. They were negative for CD20, CD79, CD19, cyclin D1, ALK, HHV8, CD2, CD3, CD4, CD5, CD8, CD33, CD43, EMA, Cytokeratin, and S-100. In situ hybridization and immunostaining for immunoglobulin heavy and light chains appeared polytypic and was difficult to interpret. Therefore a PCR based analysis of B cell clonality was performed which showed clonal IG Kappa gene rearrangements consistent with clonal $\mathrm{B}$ cell population. In the context of a metallic hip replacement, the features were those of diffuse large B cell lymphoma with chronic inflammation.

Due to clinical condition of the patient and poor prognosis, in liaison with the haematological team who advised that the patient was in the terminal phase of her illness, appropriate management would be palliation. The patient was transferred to a hospice for continuing care and support and the patient passed way after only two weeks of admission to hospice.

\section{Discussion}

Non-Hodgkin's lymphoma (NHL) is a malignant proliferation of either B or T cell lymphocytes in a disorderly fashion. Diffuse large B cell lymphoma is the most common of all lymphomas accounting for about 35\% [15]. The distribution of these tumours is predominantly nodal, but up to one-third of all NHL can be extranodal [16].

Any part of the musculoskeletal system can be affected in lymphomas and can present as a soft tissue mass resembling either infection or soft tissue tumour [5, 17]. The soft tissue involvement is more common in NHL rather than Hodgkin's lymphoma [18]. There are several theories put forward suggesting the cause of primary soft tissue lymphomas. One such hypothesis suggests that chronic inflammation involving the soft tissue such as inflammatory connective tissue disorders, viral infections, and local debris from prosthetic joint replacement implants can damage the cell membrane of macrophages. This in turn leads to the release of proinflammatory mediators which stimulate the immune system responses [19].

There are several studies which looked at increased incidence of lymphoma after total hip replacement. Gillespie et al. concluded that in the first decade following total hip replacement the incidence of tumours of the lymphatic and haemopoietic systems was significantly greater and this may be as the resultant effect of the prosthetic implants [6]. Another study by Visuri and Koskenvuo concluded that 


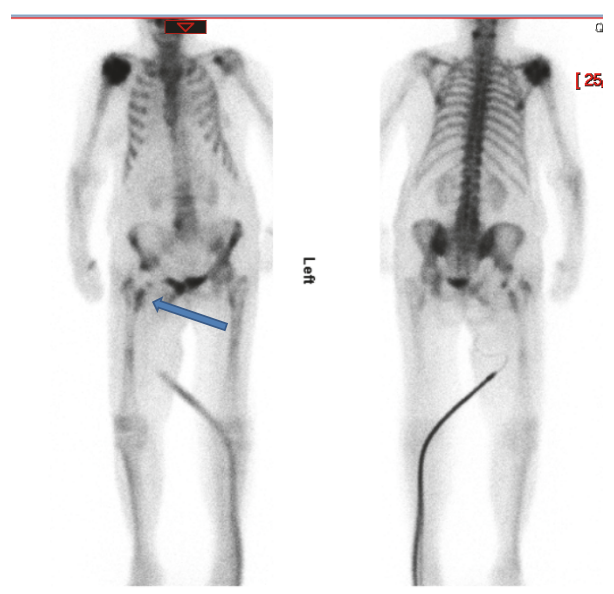

(a)

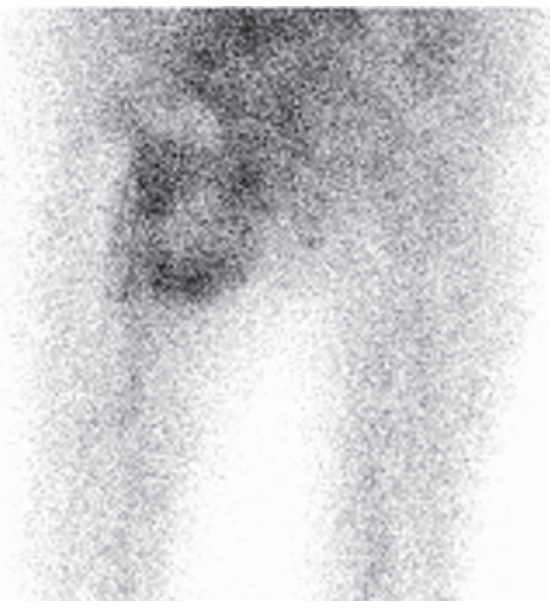

(b)

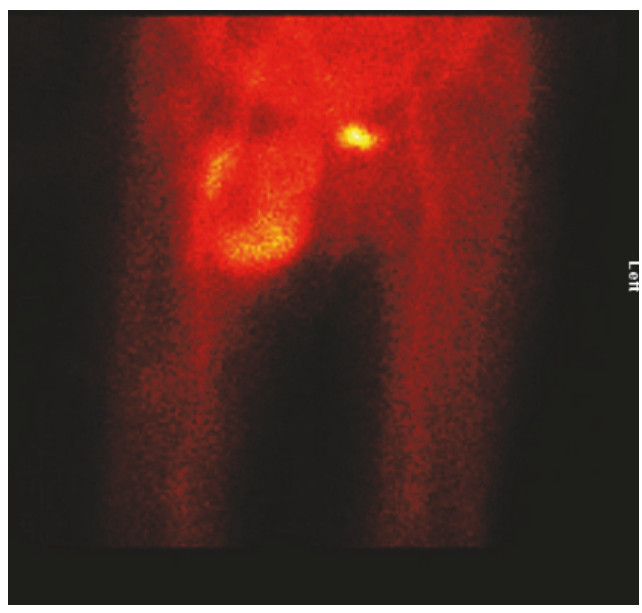

(c)

FIGURE 3: (a) Te ${ }^{99}$ bone scan showing increased uptake suggestive of infection. (b and c) The hypervascular abnormality on the early images would be in keeping with a soft tissue abscess with a necrotic centre, possibly related to infection of the right hip prosthesis.

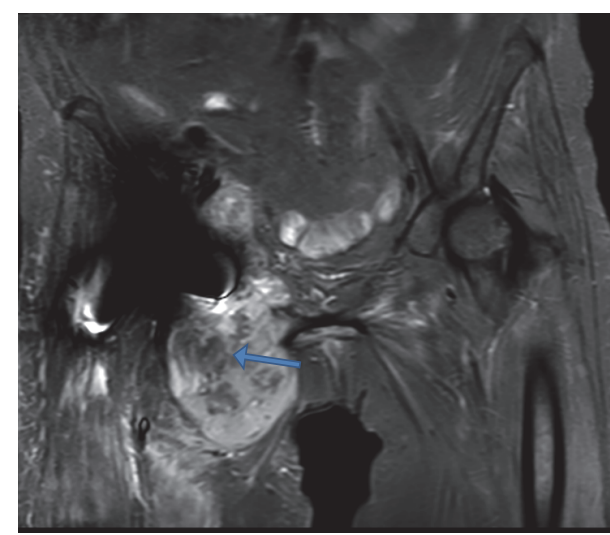

(a)

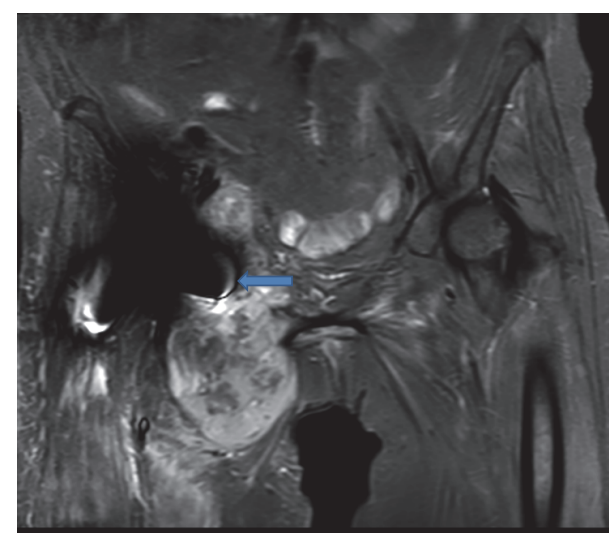

(b)

FIGURE 4: (a) T2 weighted images showing a lesion with central liquefaction necrosis. (b) T2 weighted images showing the close proximity of the lesion to the medial side of the prosthesis with effusion into the joint. 


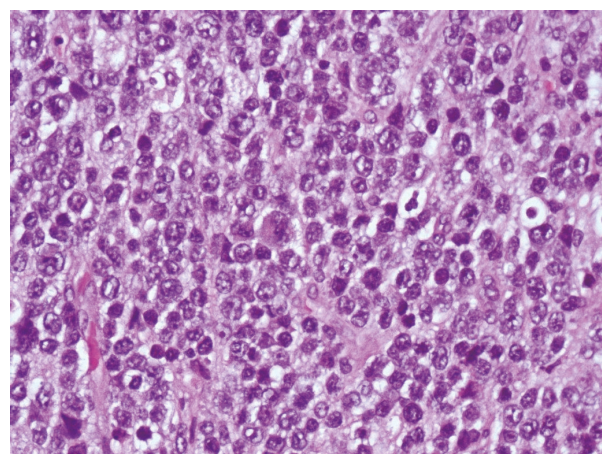

FIGURE 5: Medium sized atypical lymphoid cells with large vesicular nuclei and prominent nucleoli, some showing a hint of plasmacytoid differentiation.

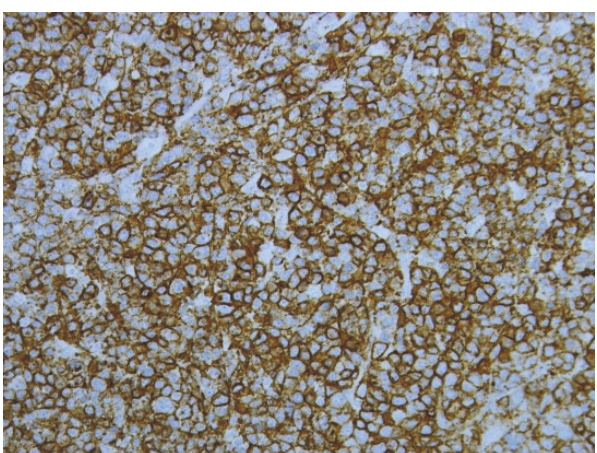

(a)

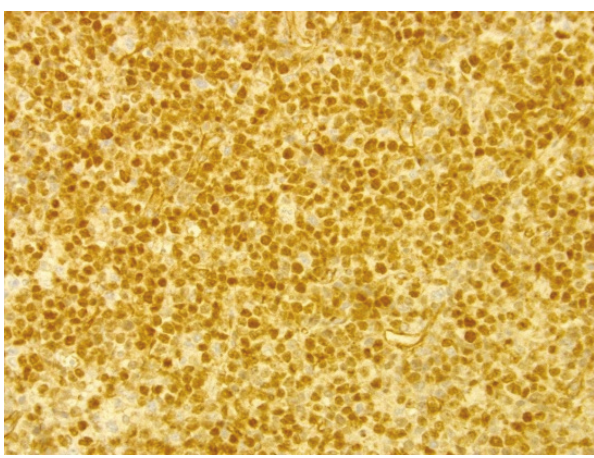

(c)

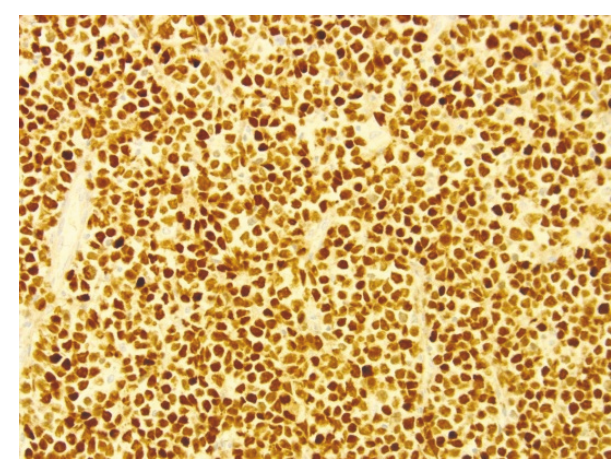

(b)

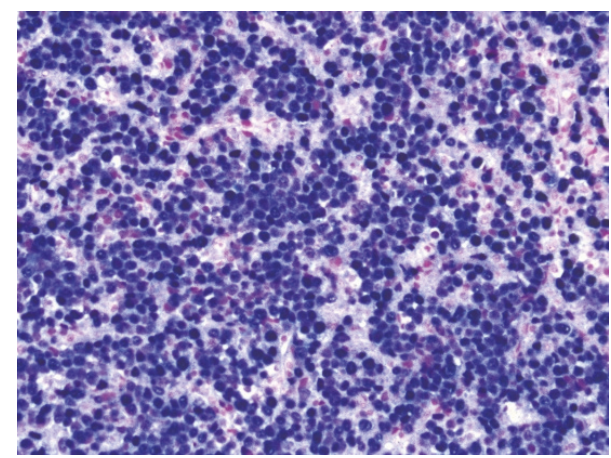

(d)

FIgURE 6: Immunostains showing positivity with CD138 (a), MUM 1 (b), PAX 5 (c), and EBV ISH (d) confirming diffuse large B cell lymphoma.

patients with a total hip replacement have an increased risk of lymphoma and leukaemia and also suggested the role of chrome-cobalt-molybdenum alloy in carcinogenesis [20]. The association of primary NHL and total hip replacement has been described in various case reports in the literature (Table 1).

Usually diffuse B cell NHL affects patients above the age of 60 years and predominantly occurs in males with a ratio of $1.5: 1[8,21]$. The systemic symptoms such as weight loss and pyrexia are usually absent [17]. The case described in this report also did not show any systemic symptoms. The incidence of involvement of the proximal femur $(27-34 \%)$ and the pelvis $(15-17 \%)$ has been reported $[22,23]$. The imaging investigations including CT and MRI scan can describe the morphology of the lesion, but a definitive diagnosis of B cell NHL is only possible by an open biopsy [24]. Interestingly in our patient the signs, symptoms, and imaging studies performed were all highly suggestive of a periprosthetic infection, but open biopsy results concluded otherwise.

One of the differential diagnoses of mass lesions after total hip replacement is a metal-on-metal pseudotumour, also known as aseptic lymphocyte-dominant vasculitis-associated lesion (ALVAL), especially around a metal-on-metal hip or knee replacement [25]. They are large focal solid or semiliquid masses around the hip prostheses. The pseudotumours mimic features of neoplasia or infection. The principal symptom is pain and there may be restricted range of movements of the hip joint. The incidence of symptomatic pseudotumours 
TABLE 1: Case studies with diffuse B cell NHL after total hip replacement.

\begin{tabular}{|c|c|c|c|c|}
\hline Case study & Age/gender & $\begin{array}{l}\text { Duration of } \\
\text { symptoms }\end{array}$ & Presenting symptoms & Treatment \\
\hline Syed et al. [9], 2002 & $75 / F$ & 7 years & $\begin{array}{l}\text { Thigh and groin pain } \\
\text { with inability to weight } \\
\text { bear }\end{array}$ & Radiotherapy \\
\hline Radhi et al. [10], 1998 & $64 / \mathrm{F}$ & 4 years & $\begin{array}{l}\text { Pain and swelling in the } \\
\text { thigh }\end{array}$ & $\begin{array}{l}\text { Chemotherapy and } \\
\text { radiotherapy }\end{array}$ \\
\hline Ito and Shimizu [11], 1999 & $80 / \mathrm{F}$ & 8 years & Painful hip & Radiotherapy \\
\hline Ganapathi et al. [12], 2001 & $85 / \mathrm{M}$ & 14 months & $\begin{array}{l}\text { Chronic discharging } \\
\text { sinus }\end{array}$ & Died before treatment \\
\hline O'Shea et al. [13], 2006 & $75 / F$ & 13 years & $\begin{array}{l}\text { Chronic discharging } \\
\text { sinus, pain, and swelling } \\
\text { of thigh }\end{array}$ & $\begin{array}{l}\text { Chemotherapy, radiotherapy, } \\
\text { and excision arthroplasty }\end{array}$ \\
\hline Hsieh et al. [14], 2007 & $30 / \mathrm{F}$ & 4 years & Painful hip & Chemotherapy \\
\hline Rajeev et al., 2016 (current study) & $72 / \mathrm{F}$ & 3 years & Painful hip & Died \\
\hline
\end{tabular}

following metal-on-metal hip arthroplasty is in the region of $5 \%$ and females are commonly affected [26, 27]. Metalon-metal pseudotumours are sterile inflammatory lesions. Excessive wear is considered the initiating process, leading to the release of nanometer sized particles. These are cytotoxic to macrophages once phagocytised and may lead to necrosis within the lesions. They are usually associated with high serum and joint fluid cobalt and chromium ion levels [28].

The other cause of psuedotumours after THR is avulsion of abductor tendons associated with fluid collection. MRI scans are diagnostic with pure fluid signals and the anatomical location of the pseudotumour [29].

The treatment of diffuse B cell NHL is combined chemotherapy and radiotherapy with good outcomes [30]. The five-year survival rate with combined modality therapy is $88 \%$ [22].

\section{Conclusion}

Primary diffuse large B cell NHL is a rare musculoskeletal malignancy. It can present atypically as a periprosthetic joint infection; therefore clinicians should have a high index of clinical suspicion to consider and include tumour pathology in the differential diagnosis.

In cases of suspicion of alternate pathology one should consider an open biopsy for a timely diagnosis and treatment.

\section{Conflicts of Interest}

The authors declare that they have no conflicts of interest.

\section{References}

[1] A. Jawa, A. E. Lieberman, C. C. N. Alexieva, and J. B. Jupiter, "Primary intra-articular non-hodgkin's lymphoma of the elbow," A case Report. Journal of Bone and Joint Surgery-Series A, vol. 88, no. 12, pp. 2730-2734, 2006.

[2] R. Vadivelu, N. Kar, M. J. Margetts, and A. H. M. Abdul-Cader, "Non-Hodgkin's lymphoma as an unexpected diagnosis in a hip arthroplasty," Archives of Orthopaedic and Trauma Surgery, vol. 122, no. 9-10, pp. 532-534, 2002.
[3] A. J. S. Watson and M. J. Cross, "Non-hodgkin lymphoma as an unexpected diagnosis after elective total knee arthroplasty," Journal of Arthroplasty, vol. 23, no. 4, pp. 612-614, 2008.

[4] R. Neri, M. Giorgetti, V. Zampa et al., "Case report. Elbow monoarthritis revealing B cell non-Hodgkin's lymphoma," Clinical Rheumatology, vol. 32, 1, no. 1, pp. 111-114, 2013.

[5] R. Singh, B. H. Al Wattar, and K. Mohanty, "A rare case of primary bone lymphoma mimicking a pelvic abscess," Annals of the Royal College of Surgeons of England, vol. 93, no. 7, pp. e141-e143, 2011.

[6] W. J. Gillespie, C. M. Frampton, R. J. Henderson, and P. M. Ryan, "The incidence of cancer following total hip replacement," Journal of Bone and Joint Surgery British Volume, vol. 70, pp. 539-542, 1988.

[7] W. J. Gillespie, D. A. Henry, D. L. O’Connell et al., "Development of hematopoietic cancers after implantation of total joint replacement," Clinical Orthopaedics and Related Research, 329, pp. S290-S296, 1996.

[8] C. Thieblemont and B. Coiffier, "Lymphoma in older patients," Journal of Clinical Oncology, vol. 25, no. 14, pp. 1916-1923, 2007.

[9] A. A. Syed, M. Agarwal, G. Fenelon, and M. Toner, "Osseous malignant non-Hodgkin's B-cell lymphoma associated with total hip replacement," Leukemia and Lymphoma, vol. 43, no. 11, pp. 2213-2216, 2002.

[10] J. M. Radhi, K. Ibrahiem, and T. Al-Tweigeri, "Soft tissue malignant lymphoma at sites of previous surgery," Journal of Clinical Pathology, vol. 51, no. 8, pp. 629-632, 1998.

[11] H. Ito and A. Shimizu, "Malignant lymphoma at the site of a total hip replacement," Orthopedics, vol. 22, pp. 82-84, 1999.

[12] M. Ganapathi, D. N. W. Lake, and A. P. Griffiths, "Periprosthetic high-grade B-cell lymphoma complicating an infected revision total hip arthroplasty," Journal of Arthroplasty, vol. 16, no. 2, pp. 229-232, 2001.

[13] K. O'Shea, S. R. Kearns, A. Blaney, P. Murray, H. A. Smyth, and J. P. McElwain, "Periprosthetic malignancy as a mode of failure in total hip arthroplasty," Journal of Arthroplasty, vol. 21, no. 6, pp. 926-930, 2006.

[14] T.-C. Hsieh, C.-H. Kao, K.-Y. Yen, and S.-S. Sun, "Osteomyelitismimicking primary bone lymphoma at hip prosthetic site," Clinical Nuclear Medicine, vol. 32, no. 7, pp. 543-544, 2007.

[15] J. R. Anderson, J. O. Armitage, and D. D. Weisenburger, "Epidemiology of the non-Hodgkin lymphomas: distributions of the 
major subtypes differ by geographic locations. non-hodgkin's lymphoma classification project," Annals of Oncology, vol. 9, no. 7, pp. 717-720, 1998.

[16] R. Otter, W. B. J. Gerrits, M. M. V. D. Sandt, J. Hermans, and R. Willemze, "Primary extranodal and nodal non-Hodgkin's lymphoma. a survey of a population-based registry," European Journal of Cancer and Clinical Oncology, vol. 25, no. 8, pp. 12031210, 1989.

[17] J. K. O’Neill, V. Devaraj, D. A. T. Silver, P. Sarsfield, and C. A. Stone, "Extranodal lymphomas presenting as soft tissue sarcomas to a sarcoma service over a two-year period," Journal of Plastic, Reconstructive and Aesthetic Surgery, vol. 60, no. 6, pp. 646-654, 2007.

[18] M. Katsura, H. Nishina, Y. Shigemori, and T. Nakanishi, "Extranodal lymphoma originating in the gluteal muscle with adjacent bone involvement and mimicking a soft tissue sarcoma," International Journal of Surgery Case Reports, vol. 7, pp. 161-164, 2015.

[19] T. Visuri, H. Borg, P. Pulkkinen, P. Paavolainen, and E. Pukkala, "A retrospective comparative study of mortality and causes of death among patients with metal-on-metal and metal-onpolyethylene total hip prostheses in primary osteoarthritis after a long-term follow-up," BMC Musculoskeletal Disorders, vol. 11, article 78, 2010.

[20] T. Visuri and M. Koskenvuo, "Cancer risk after McKee-Farrar total hip replacement," Orthopedics, vol. 14, pp. 137-142, 1991.

[21] S. Desai, N. A. Jambhekak, C. S. Soman, and S. H. Advani, "Primary lymphoma of bone: a clinicopathologic study of 25 cases reported over 10 years," Journal of Surgical Oncology, vol. 46, no. 4, pp. 265-269, 1991.

[22] K. Beal, L. Allen, and J. Yahalom, "Primary bone lymphoma: treatment results and prognostic factors with long-term followup of 82 patients," Cancer, vol. 106, no. 12, pp. 2652-2656, 2006.

[23] E. Demircay, F. J. Hornicek Jr., H. J. Mankin, and H. Degroot III, "Malignant lymphoma of bone: a review of 119 patients," Clinical Orthopaedics and Related Research, vol. 471, no. 8, pp. 26842690, 2013.

[24] H. Xu, K. Xu, R. Wang, and X. Liu, "Primary pulmonary diffuse large b-cell lymphoma on FDG PET/CT-MRI and DWI," Medicine (United States), vol. 94, no. 29, Article ID e1210, 2015.

[25] P. Campbell, E. Ebramzadeh, S. Nelson, K. Takamura, K. de Smet, and H. C. Amstutz, "Histological features of pseudotumor-like tissues from metal-on-metal hips," Clinical Orthopaedics and Related Research, vol. 468, no. 9, pp. 2321-2327, 2010.

[26] A. J. Hart, K. Satchithananda, A. D. Liddle et al., "Pseudotumors in association with well-functioning metal-on-metal hip prostheses: a case-control study using three-dimensional computed tomography and magnetic resonance imaging," Journal of Bone and Joint Surgery-Series A, vol. 94, no. 4, pp. 317-325, 2012.

[27] D. H. Williams, N. V. Greidanus, B. A. Masri, C. P. Duncan, and D. S. Garbuz, "Prevalence of pseudotumor in asymptomatic patients after metal-on-metal hip arthroplasty," Journal of Bone and Joint Surgery-Series A, vol. 93, no. 23, pp. 2164-2171, 2011.

[28] Y.-M. Kwon, S. J. Ostlere, P. McLardy-Smith, N. A. Athanasou, H. S. Gill, and D. W. Murray, “'Asymptomatic' Pseudotumors after metal-on-metal hip resurfacing arthroplasty. prevalence and metal ion study," Journal of Arthroplasty, vol. 26, no. 4, pp. 511-518, 2011.

[29] C. W. A. Pfirrmann, H. P. Notzli, C. Dora, J. Hodler, and M. Zanetti, "Abductor tendons and muscles assessed at MR imaging after total hip arthroplasty in asymptomatic and symptomatic patients," Radiology, vol. 235, no. 3, pp. 969-976, 2005.
[30] D. R. Ford, D. Wilson, S. Sothi, R. Grimer, and D. Spooner, "Primary bone lymphoma-treatment and outcome," Clinical Oncology, vol. 19, no. 1, pp. 50-55, 2007. 


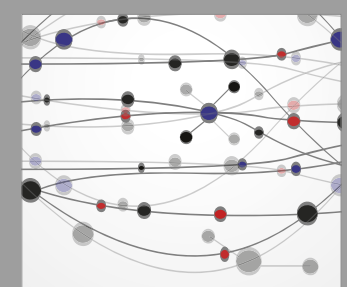

The Scientific World Journal
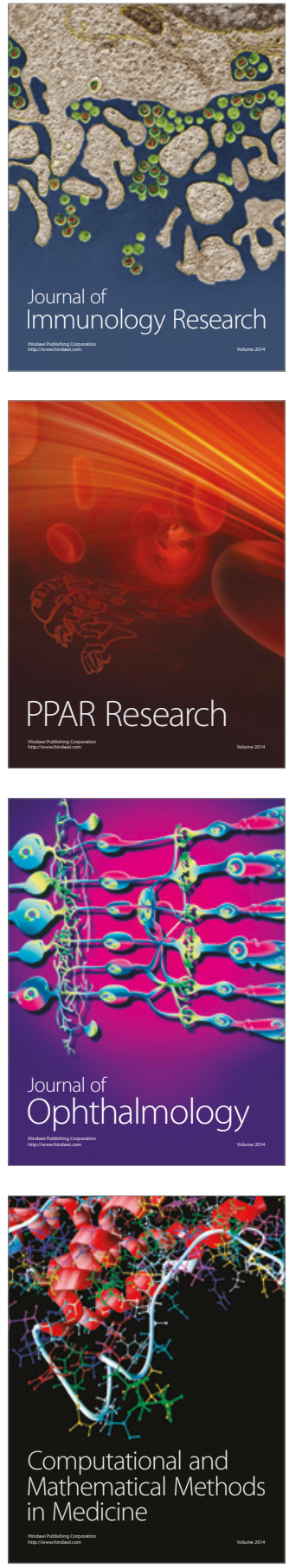

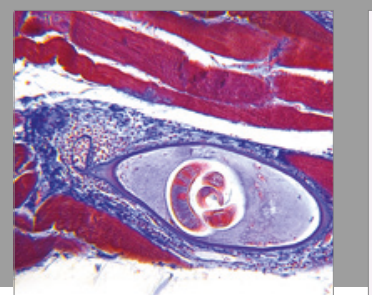

Gastroenterology Research and Practice
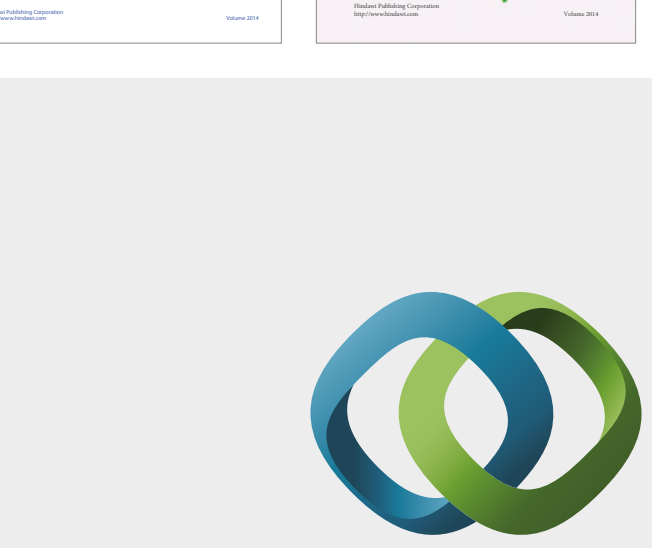

\section{Hindawi}

Submit your manuscripts at

https://www.hindawi.com
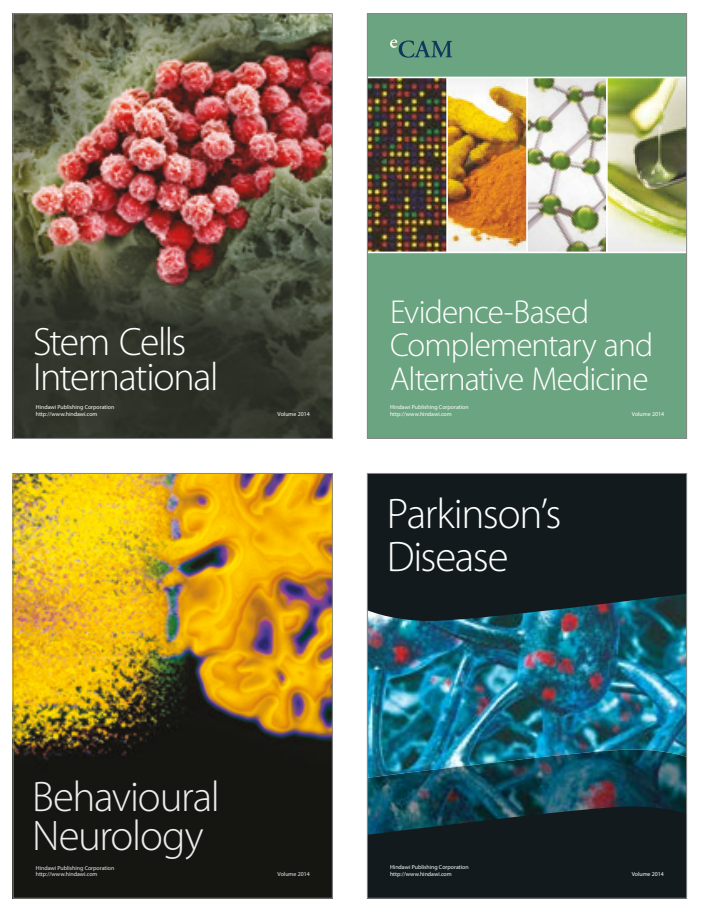
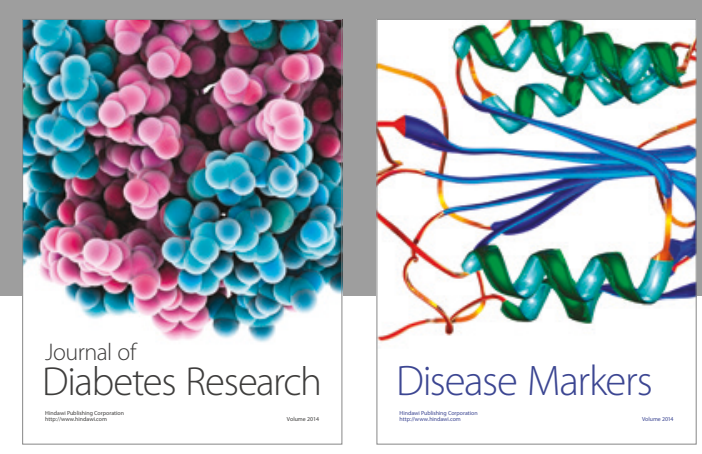

Disease Markers
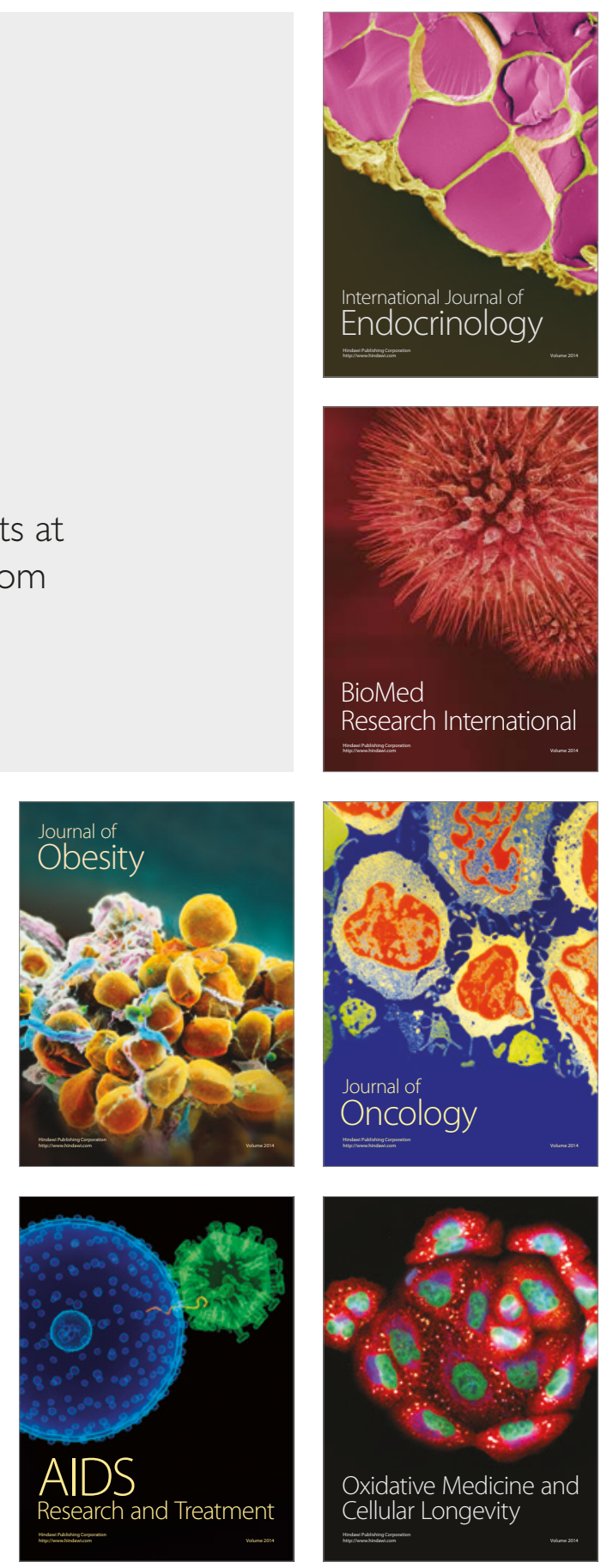